University of Wollongong

Research Online

Faculty of Engineering and Information

Faculty of Engineering and Information

Sciences - Papers: Part A

Sciences

2013

\title{
A nonconjugated bridge in dimer-sensitized solar cells retards charge recombination without decreasing charge injection efficiency
}

Kenji Sunahara

Shinshu University

Matthew J. Griffith

University Of Wollongong, mjg48@uow.edu.au

Takayuki Uchiyama

Shinshu University

Pawel Wagner

University of Wollongong, pawel@uow.edu.au

David L. Officer

University of Wollongong, davido@uow.edu.au

See next page for additional authors

Follow this and additional works at: https://ro.uow.edu.au/eispapers

Part of the Engineering Commons, and the Science and Technology Studies Commons

Research Online is the open access institutional repository for the University of Wollongong. For further information contact the UOW Library: research-pubs@uow.edu.au 


\title{
A nonconjugated bridge in dimer-sensitized solar cells retards charge recombination without decreasing charge injection efficiency
}

\begin{abstract}
Dye sensitized solar cells (DSSCs) employing a dimer porphyrin, which was synthesised with two porphyrin units connected without conjugation, have shown that both porphyrin components can contribute to photocurrent generation, that is, more than $50 \%$ internal quantum efficiency. In addition, the open-circuit voltage (Voc) of the DSSCs was higher than that of DSSCs using monomer porphyrins. In this paper, we first optimized cell structure and fabrication conditions. We obtained more than $80 \%$ incident photon to current conversion efficiency from the dimer porphyrin sensitized DSSCs and higher Voc and energy conversion efficiency than monomer porphyrin sensitized solar cells. To examine the origin of the higher Voc, we measured electron lifetime in the DSSCs with various conditions, and found that the dimer system increased the electron lifetime by improving the steric blocking effect of the dye layer, whilst the lack of a conjugated linker prevents an increase in the attractive force between conjugated sensitizers and the acceptor species in the electrolyte. The results support a hypothesis; dispersion force is one of the factors influencing the electron lifetime in DSSCs.
\end{abstract}

\section{Keywords}

efficiency, decreasing, without, recombination, charge, retards, cells, injection, solar, nonconjugated, sensitized, dimer, bridge

\section{Disciplines}

Engineering | Science and Technology Studies

\section{Publication Details}

Sunahara, K., Griffith, M. J., Uchiyama, T., Wagner, P., Officer, D. L., Wallace, G. G., Mozer, A. J. \& Mori, S. (2013). A nonconjugated bridge in dimer-sensitized solar cells retards charge recombination without decreasing charge injection efficiency. ACS Applied Materials and Interfaces, 5 (21), 10824-10829.

\section{Authors}

Kenji Sunahara, Matthew J. Griffith, Takayuki Uchiyama, Pawel Wagner, David L. Officer, Gordon G. Wallace, Attila J. Mozer, and Shogo Mori 


\section{A Non-Conjugated Bridge in Dimer Sensitised Solar Cells to}

\section{Retard Charge Recombination without Decreasing Charge}

\section{Injection Efficiency}

Kenji Sunahara, ${ }^{\dagger}$ Matthew J. Griffith, ${ }^{\S}$ Takayuki Uchiyama, $^{\dagger}$ Pawel Wagner, $^{\S}$ David L. Officer, ${ }^{\S}$ Gordon G. Wallace, ${ }^{\S}$ Attila J. Mozer, ${ }^{\S, *}$ and Shogo Mori ${ }^{\dagger, *}$

Division of Chemistry and Materials, Faculty of Textile Science and Technology, Shinshu University, Ueda, Nagano, 386-8567, Japan.

ARC Centre of Excellence for Electromaterials Science and Intelligent Polymer Research Institute, University of Wollongong, Innovation Campus, Squires Way, Fairy Meadow, NSW, 2519, Australia

${ }^{\dagger}$ Faculty of Textile Science and Technology, Shinshu University

$\S$ ARC Centre of Excellence for Electromaterials Science, University of Wollongong

\section{RECEIVED DATE}

CORRESPONDING AUTHOR FOOTNOTE

Dr Attila Mozer: Innovation Campus, University of Wollongong, Squires Way, Fairy Meadow, NSW, 2519, Australia. Telephone: +61 (2) 4298 1429. Email: attila@uow.edu.au 
Associate Professor S. Mori: Faculty of Textile Science and Technology, Shinshu University, Ueda, Nagano, 386-8567, Japan. Telephone: +81 (0)268 215 818. Email: shogmori@shinshu-u.ac.jp

\section{ABSTRACT}

Dye sensitised solar cells (DSSCs) employing a dimer porphyrin, which was synthesised with two porphyrin units connected without conjugation, have shown that both porphyrin components can contribute to photocurrent generation, that is, more than $50 \%$ incident photon to current conversion (IPCE) efficiency. In addition, the open-circuit voltage $\left(V_{\text {oc }}\right)$ of the DSSCs was higher than that of DSSCs using monomer porphyrins. In this paper, we first optimized cell structure and fabrication conditions and obtained more than 80 \% IPCE from the dimer porphyrin sensitized DSSCs and higher $V_{\text {oc }}$ and energy conversion efficiency than monomer porphyrin sensitized solar cells. In order to examine the origin of the higher $V_{\text {oc }}$, we measured electron lifetime in the DSSCs with various conditions, and found that the dimer system increased the electron lifetime by improving the steric blocking effect of the dye layer, whilst the lack of a conjugated linker prevents an increase in the attractive force between conjugated sensitisers and the acceptor species in the electrolyte. The results support a hypothesis; dispersion forces are one of the factors influencing the electron lifetime in DSSCs.

KEYWORDS: dimer, dye sensitised solar cells, electron lifetime, porphyrin, dispersion force. 


\section{INTRODUCTION}

Sensitisation of nanocrystalline oxides with organic and inorganic light harvesting compounds is a promising pathway for the development of low cost renewable energy conversion devices. ${ }^{[1]}$ One of the challenges in the development of highly efficient dye-sensitised solar cells (DSSCs) is to retard charge recombination. ${ }^{[2]}$ Whilst the recombination process is dependent on a range of factors, one of the key materials controlling this reaction has been shown to be the sensitisers themselves. ${ }^{[3-4]}$ We have previously reported that the open circuit voltage $\left(V_{\text {oc }}\right)$ of porphyrin-based DSSCs is typically lower than those of other efficient ruthenium complex dyes. ${ }^{[5]}$ This was attributed to a short lifetime of $\mathrm{TiO}_{2}$ electrons primarily recombining with triiodide $\left(\mathrm{I}_{3}{ }^{-}\right)$ions, the acceptor species in the electrolyte. This recombination reaction has been found to be a general problem for many organic sensitisers limiting their open circuit voltage. ${ }^{[6-7]}$ The major reason for this lower photovoltage is that adsorption of sensitisers on the $\mathrm{TiO}_{2}$ surface acts to facilitate charge recombination with the redox mediator. It has been proposed that one origin of this enhanced recombination is the dispersion forces on the sensitiser attracting the acceptor species to the $\mathrm{TiO}_{2}$ surface region and increasing the probability of reverse charge transfer. ${ }^{[8]}$ Since this dispersion force scales with the length of the $\pi$ conjugation unit, ${ }^{[9]}$ sensitisers with a smaller size are desired to minimize recombination. However such dyes have narrow absorption spectra, which prevent their use as efficient sensitisers in solar cells. Most previous attempts to decrease the charge recombination in DSSCs have therefore concentrated on insulating the $\mathrm{TiO}_{2}$ with surface treatments, ${ }^{[10-12]}$ small co-adsorber molecules, ${ }^{[13-16]}$ or to add alkyl chains to sensitisers to prevent the approach of the electron acceptor species to the $\mathrm{TiO}_{2}$ surface. ${ }^{[17-20]}$ Recently, such strategies were incorporated into the design of a porphyrin sensitiser to produce a record power conversion efficiency of $12.1 \%$. ${ }^{[21]}$ 
Recently, dimer sensitisers have been paid attentions. One motivation to apply dimers for DSSCs is to increase the absorption spectrum. For this purpose, two molecules are connected with a conjugated linker. The other motivation is to increase light absorption coefficients of sensitisers. For this case, molecules are connected using a non-conjugated bridge. By increasing the coefficients, the thickness of the porous electrodes can be reduced. Table 1 summarizes recently published data for dimer sensitised solar cells. ${ }^{[22-26]}$ As expected, using conjugated linkers results in the enhancement of the absorption spectrum, while it seems to result in the decrease of $V_{\text {oc. }}$ On the other hand, dimer sensitisers using nonconjugated linkers showed higher $V_{\text {oc }}$ than monomer sensitisers. If the blocking effect of dye layers dominates the process of charge recombination, employing dimers is always expected to result in a higher $V_{\text {oc }}$ due to their larger molecular size. However, the data on Table 1 show that it is not always the case. If dispersion forces affect the charge recombination and the influence of such forces can compete with the blocking effect, then the results on Table 1 would be more easily rationalized. On other hand, the dispersion force theory has not been accepted widely as one of the factors influencing the recombination. One of the aims of this paper is to examine the role of dispersion forces in charge recombination by using a non-conjugated bridge in dimer sensitised solar cells.

Table 1. Summary of reported performance of DSSCs employing dimer sensitisers.

\begin{tabular}{|c|c|c|c|c|c|c|c|}
\hline Authors & Dye & $\begin{array}{c}\text { IPCE }_{\max } \\
(\%) \\
\end{array}$ & $\begin{array}{c}\text { IPCE Onset } \\
(\mathrm{nm})\end{array}$ & $\begin{array}{c}J_{\text {sc }}(\mathbf{m A} \\
\left.\mathbf{c m}^{-2}\right) \\
\end{array}$ & $\begin{array}{c}V_{\text {oc }} \\
(\mathrm{mV})\end{array}$ & Efficiency & $\begin{array}{c}\text { Ref } \\
\#\end{array}$ \\
\hline \multirow[t]{2}{*}{ Warnan et. al. } & Dimer & 40 & 745 & 11.6 & 535 & 4.6 & 22 \\
\hline & Monomer & 30 & 730 & 9.25 & 545 & 3.6 & \\
\hline \multirow[t]{2}{*}{ Park et. al } & Dimer & $40-50$ & 700 & 10.9 & 600 & 4.2 & 23 \\
\hline & \multicolumn{6}{|c|}{ No monomer data reported } & \\
\hline \multirow[t]{3}{*}{ Wu et. al } & Dimer & 30 & 900 & 9.66 & 680 & 4.7 & 24 \\
\hline & Monomer 1 & 80 & 650 & 16.5 & 734 & 5.8 & \\
\hline & Monomer 2 & 80 & 720 & 16.8 & 758 & 8.8 & \\
\hline \multirow[t]{2}{*}{ Mai et. al } & Dimer & 70 & 710 & 12.9 & 650 & 5.2 & 25 \\
\hline & Monomer & $60-70$ & 680 & 10.9 & 710 & 5.1 & \\
\hline \multirow[t]{2}{*}{ Liu et. al } & Dimer & 60 & 850 & 14.3 & 550 & 5.2 & 26 \\
\hline & \multicolumn{6}{|c|}{ No monomer data reported } & \\
\hline
\end{tabular}




\section{EXPERIMENTAL}

Materials. Figure 1 shows the structure of dyes employed in this study. Porphyrin dyes P12 (5,10,15,20-Tetra(3,5-dimethylphenyl)-2-(2-(4-carboxylphenyl)ethenyl)porphyrinato zinc (II)), P199 ((5,10,15-tri(4-methylphenyl)-20-(4-(2-cyano-2-carboxylethenylphenyl)porphyrinato zinc (II)) and dimer $\boldsymbol{P 1 0}$ were prepared as previously reported. ${ }^{[27]}$

DSC Fabrication. $\mathrm{TiO}_{2}$ films were prepared on fluorine-doped tin oxide (FTO) substrates (Nippon Sheet Glass, $\mathrm{R}_{\mathrm{s}} \leq 9.5 \Omega \mathrm{sq}^{-1}$ ) using a doctor-blade technique and were sintered at $550^{\circ} \mathrm{C}$ for 30 minutes in air. DSSCs for high efficiency were prepared with a $\mathrm{TiO}_{2}$ nano-particle paste from Sumito Osaka Cement Co. Ltd for a transparent layer and with a $400 \mathrm{~nm} \mathrm{TiO}_{2}$ particles (CCIC, Japan) for a scattering layer. Thickness of $\mathrm{TiO}_{2}$ electrode, dye bath immersion time, and concentration of chenodeoxycholic acid (CDCA) were varied. DSSCs for lifetime measurements were prepared using around $5.4 \mu \mathrm{m}$ transparent $\mathrm{TiO}_{2}$ layer (Nanoxide-T, Solaronix) without scattering layer. Dye sensitisation was achieved by immersion of $\mathrm{TiO}_{2}$ films at around $80{ }^{\circ} \mathrm{C}$ into $0.2 \mathrm{mM}$ or $0.02 \mathrm{mM}$ ethanolic solutions of porphyrin dyes without CDCA and leaving at room temperature for 2 hours or 30 min, respectively. Sandwichtype DSSCs were assembled using a thermal adhesive film and Pt-sputtered FTO-glass counter electrodes. Electrolyte solutions of varying composition were injected between the electrodes to complete devices. Electrolyte compositions employed in this study included:

Ia 0.6 M 1,2-dimethyl-3-propylimidazolium (DMPImI), 0.5 M 4-tert-butylpyridine (tBP), $0.1 \mathrm{M}$ LiI and $0.05 \mathrm{M} \mathrm{I}_{2}$ in acetonitrile

Ib 0.6 M 1-butyl-2-methyl-3-propylimidazolium (BMPImI), 0.5 M 4-tert-butylpyridine (tBP), 0.1 $\mathrm{M} \mathrm{LiI}$ and $0.05 \mathrm{M} \mathrm{I}_{2}$ in acetonitrile

II 0.7 M BMPImI, 0.3 M tBP and 0.05 $\mathrm{M} \mathrm{I}_{2}$ in acetonitrile

III 0.7 M DMPImI and 0.05 $\mathrm{M} \mathrm{I}_{2}$ in acetonitrile 
DSSC Characterization. Current-voltage curves were recorded using a Keithley 2400 source measure unit with a simulated $100 \mathrm{~mW} \mathrm{~cm}^{-2}$ air mass AM 1.5 light source (YSS-100A, Yamashita Denso).

Electron Lifetime and Diffusion Coefficient Measurements. Electron lifetimes and diffusion coefficients were determined using stepped light-induced measurements of photocurrent and photovoltage transients (SLIM-PCV). ${ }^{[28]}$ Measurements were performed using a $635 \mathrm{~nm}$ diode laser illuminating the entire DSSC active area. Photocurrent and photovoltage transients were induced by the small stepwise $(\leq 10 \%)$ change of the laser intensity, controlled by a PC using a digital-to-analogue converter. Induced transients were measured by a fast multimeter (AD7461A, Advantest). Electron densities at each laser illumination intensities were determined by a charge extraction method in which the light source is switched off at the same time the DSSC is switched from open to short circuit. ${ }^{[29]}$ The resulting current was integrated, with the electron density calculated from the amount of charge extracted.

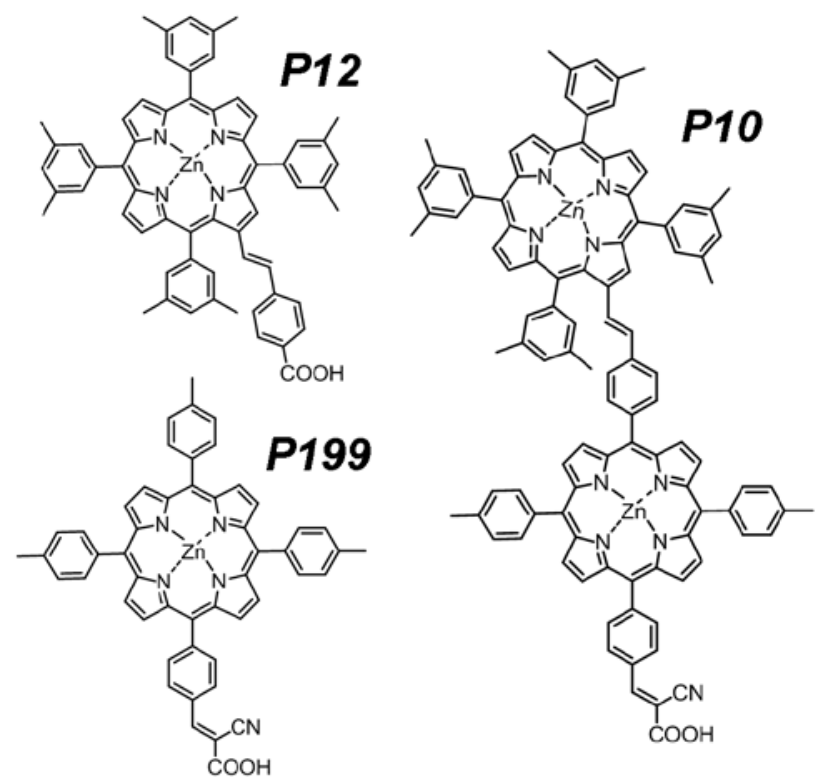

Figure 1: Chemical structures of porphyrin dyes P10, P12, P199 employed in this study. 


\section{RESULTS AND DISCUSSION}

\section{Optimising Device Fabrication Conditions for Dimer-sensitised Solar Cells}

First, we checked the effect of dye bath concentration and immersion time on solar cells performance (Figure S1 and S2 in Supporting Information) using electrolyte Ia. With initial increases in both concentration and time, the values of $J_{\mathrm{sc}}$ were increased for both the dimer and monomer sensitised solar cells. Further increases in these parameters then resulted in a decrease in the values of $J_{\mathrm{sc}}$. The decreased $J_{\mathrm{sc}}$ could be due to an undesired interaction among adsorbed dyes. Secondly, we examined the effect of co-adsorbent and immersion time. The concentration of dye was fixed and electrolyte Ia was employed. Table 2 summarizes the performance. The addition of CDCA increased the $J_{\mathrm{sc}}$ for DSSCs using both the dimer and monomer. However, longer immersion times again resulted in a decrease of the $J_{\mathrm{sc}}$. The concentration ratio of CDCA to dye was varied and a 10:1 ratio was found to give the highest $J_{\mathrm{sc}}$. The addition of a scattering layer to the $\mathrm{TiO}_{2}$ films increased the $J_{\mathrm{sc}}$ by $20 \%$. The thickness of the transparent layer was varied between 3.5 and $5.6 \mu \mathrm{m}$, and comparable values were obtained from 4.8 and $5.6 \mu \mathrm{m}$, suggesting the optimal thickness exists around these values. The DSSCs using the dimer always showed higher values of $V_{\text {oc }}$ than those of DSSCs using monomers. Figure 2 shows the I-V curves and IPCE of the optimized DSSCs using dimer and monomers. Both the dimer and monomer DSSCs showed more than 80 \% IPCE while the dimer DSSCs showed higher values of $V_{\text {oc }}$. The dimer DSSCs resulted in $5.5 \%$ energy conversion efficiency, and the value was higher than those of the monomer DSSCs. The trend of the $V_{\text {oc }}$ was the same to what we reported previously. ${ }^{[27]}$ Comparable values of $J_{\text {sc }}$ from both the dimer and monomer DSSCs at optimized cells are expected because the range of their respective absorption spectra is the same. However, we note that more than 80 \% IPCE from the dimer DSSCs was quite unexpected, as the dimer was made by connecting two monomers having similar LUMO levels and the bridge was not conjugated. We have shown previously that both the monomer and dimer examined here suffer from sub-nanosecond charge recombination. ${ }^{[27]}$ Thus, the 
increased IPCE using CDCA is probably caused by the retardation of the fast recombination with dye cations.

Table 2. Performance of DSSCs under one sun conditions.

\begin{tabular}{cccccccc} 
Dye & $\begin{array}{c}\text { Dye/CDCA } \\
\text { ratio }^{[\mathrm{a}]}\end{array}$ & $\begin{array}{c}\text { Dye bath } \\
\text { immersio } \\
\text { n time } \\
\text { /min }\end{array}$ & $\begin{array}{c}\text { Thickness }^{[\mathrm{b}]} \\
/ \mu \mathrm{m}\end{array}$ & $V_{\text {oc }} / \mathrm{V}$ & $\begin{array}{c}I_{\mathrm{sc}} / \\
\mathrm{mAcm}^{-2}\end{array}$ & FF & $\begin{array}{c}\text { Efficiency } \\
\text { [c] } \%\end{array}$ \\
\hline P10 & $1: 0$ & 45 & $4.7+6$ & 0.655 & 8.8 & 0.73 & 4.2 \\
P10 & $1: 0$ & 120 & $4.7+6$ & 0.651 & 9.6 & 0.71 & 4.5 \\
\hline P10 & $1: 2$ & 45 & $4.4+6$ & 0.677 & 9.8 & 0.73 & 4.8 \\
P10 & $1: 2$ & 120 & $4.4+6$ & 0.668 & 9.8 & 0.68 & 4.4 \\
P10 & $1: 2$ & 360 & $4.0+6$ & 0.677 & 8.6 & 0.68 & 4.0 \\
\hline P10 & $1: 10$ & 45 & $4.6+6$ & 0.685 & 10.4 & 0.71 & 5.1 \\
P10 & $1: 10$ & 120 & $4.8+6$ & 0.685 & 10.1 & 0.68 & 4.7 \\
P10 & $1: 10$ & 360 & $3.7+6$ & 0.677 & 8.6 & 0.68 & 4.0 \\
\hline P12 & $1: 0$ & 45 & $4.8+6$ & 0.634 & 7.3 & 0.73 & 3.4 \\
P12 & $1: 0$ & 120 & $5.5+6$ & 0.622 & 8.9 & 0.72 & 4.0 \\
P12 & $1: 0$ & 360 & $4.8+6$ & 0.596 & 6.6 & 0.74 & 2.9 \\
\hline P12 & $1: 2$ & 45 & $4.4+6$ & 0.647 & 8.5 & 0.73 & 4.0 \\
P12 & $1: 2$ & 120 & $4.6+6$ & 0.622 & 8.9 & 0.74 & 4.1 \\
P12 & $1: 2$ & 360 & $3.8+6$ & 0.617 & 8.4 & 0.72 & 3.8 \\
\hline P10 & $1: 2$ & 45 & $4.8+0$ & 0.681 & 7.9 & 0.68 & 3.7 \\
P12 & $1: 2$ & 45 & $4.7+0$ & 0.651 & 6.1 & 0.71 & 2.8 \\
\hline P10 & $1: 10$ & 45 & $3.5+4$ & 0.702 & 10.3 & 0.70 & 5.1 \\
P10 & $1: 10$ & 45 & $4.8+4$ & 0.698 & 11.0 & 0.71 & 5.5 \\
P10 & $1: 10$ & 45 & $5.6+4$ & 0.698 & 10.8 & 0.72 & 5.5 \\
\hline P12 & $1: 10$ & 45 & $5.6+4$ & 0.638 & 9.5 & 0.74 & 4.5 \\
P199 & $1: 10$ & 45 & $5.6+4$ & 0.634 & 10.1 & 0.73 & 4.6 \\
P10 & $1: 100$ & 45 & $5.7+4$ & 0.694 & 9.9 & 0.73 & 5.0 \\
\hline
\end{tabular}

[a] Concentration ratio in dye bath. The concentration of dye was fixed at $0.2 \mathrm{mM}$ in EtOH.

[b] Thickness of transparent and scattering $\mathrm{TiO}_{2}$ layers.

[c] A mask was placed on the cells. The projected area of the $\mathrm{TiO}_{2}$ was about $0.2 \mathrm{~cm}^{2}$, and the aperture area of the mask was $0.160 \mathrm{~cm}^{2}$. 

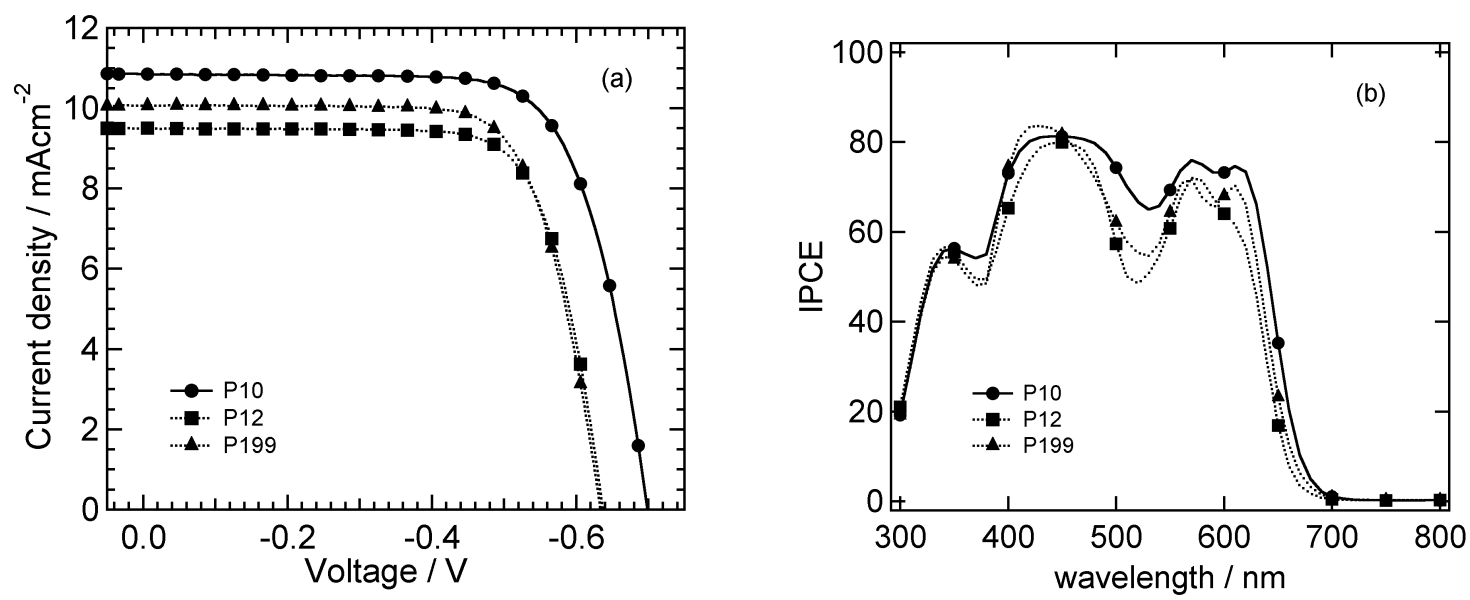

Figure 2. I-V curves (a) and IPCE (b) of the optimized DSSCs using dimer (P10) and monomers (P12 and P199).

\section{Electron Lifetime in DSSCs}

In previous section, while the cell fabrication conditions were varied, the values of the $V_{\text {oc }}$ from the dimer DSSCs were always higher than the values from the monomer DSSCs. The electron lifetime in the DSSCs were also measured, showing the electron lifetime in the dimer DSSCs always showed longer values regardless of the co-adsorption of CDCA and the addition of scattering layers to the $\mathrm{TiO}_{2}$ films (Figure S3 and S4). In order to examine the origin of the longer electron lifetime, we compared here the electron lifetime in the DSSCs with various electrolyte conditions and different amount of dyes. To simplify the system, we employed cells without any scattering layers or CDCA. The performance of the DSSCs employing electrolyte Ia without scattering layer and CDCA are shown in Table 3 and Figure S5, and the trend was the same with the I-V curves in Figure 2.

Electron lifetimes and diffusion coefficients for DSSCs prepared using the monomer and dimer porphyrin sensitisers are shown in Figure 3. All measurements were performed 3 times, with the error in the resultant data points found to be less than $30 \%$ of the values. At a matched electron density of $6 \times$ $10^{17} \mathrm{~cm}^{-3}$, the lifetime of dimer DSSCs was found to be higher than that of both monoporphyrins by an 
order of magnitude. The increased electron lifetime using the dimer may originate from slower electron transport within the $\mathrm{TiO}_{2}$ in a trap-controlled recombination mechanism. ${ }^{[30]}$ Figure 3(c) shows that there are only minimal differences observed in the diffusion coefficients of DSSCs constructed from each dye system when plotted as a function of $J_{\mathrm{sc}}$. This result indicates that variation in the charge transport is not the main origin of the increased lifetime for the dimer DSSCs. The plots of $V_{\mathrm{oc}}$ versus electron density in the $\mathrm{TiO}_{2}$ film displayed no differences in either the slope or the y-intercept for DSSCs employing any of the three dyes (Figure 3(d)). This result demonstrates that the density of trap states ${ }^{[31]}$ and the $\mathrm{TiO}_{2}$ conduction band-edge potential $\left(E_{\mathrm{CB}}\right)$ are nearly identical for DSSCs prepared using porphyrin dyes P199, P12 and P10. The improved device $V_{\text {oc }}$ observed in the dimer DSSCs is due to an increased electron density in the $\mathrm{TiO}_{2}$ film caused by the increased electron lifetime.

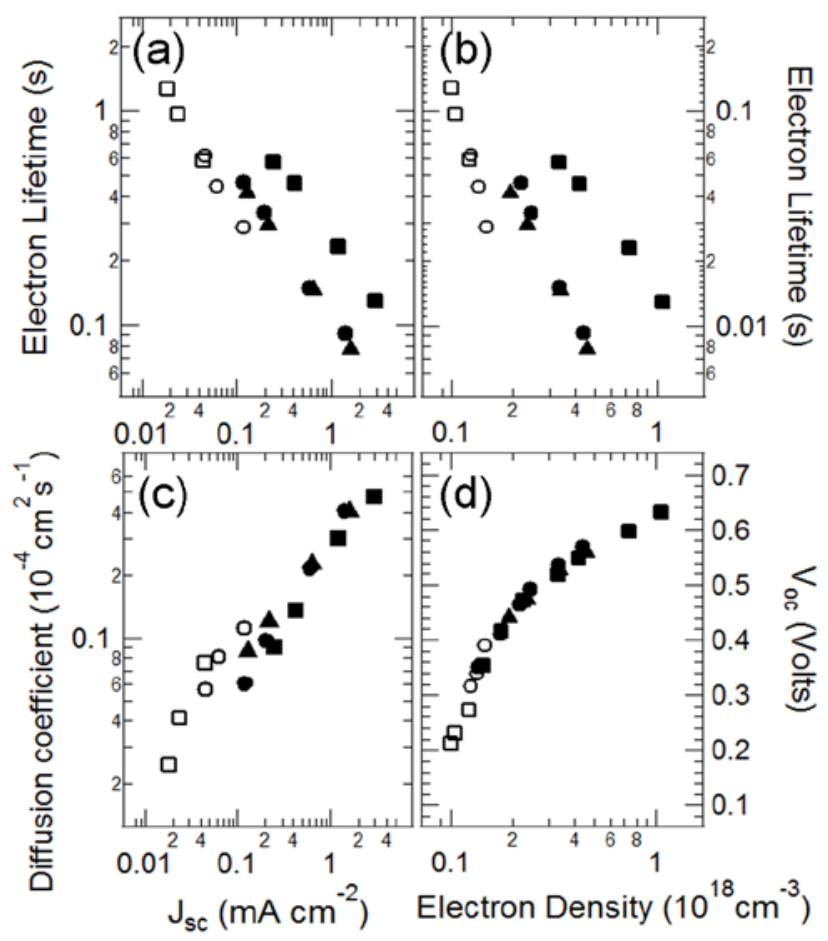

Figure 3. Electron lifetime versus (a) $J_{\mathrm{sc}}$, or (b) electron density; electron diffusion coefficient versus (c) $J_{\mathrm{sc}}$, and (d) $V_{o c}$ versus electron density for DSSCs prepared with $P 199$ (circles), P12 (triangles) and $\boldsymbol{P 1 0}$ (squares). Measurements using reduced dye surface concentrations of $\boldsymbol{P 1 9 9}$ (open circles) and $\boldsymbol{P 1 0}$ (open squares) are also shown. 
Previous studies have proposed that the following three parameters are the major factors which influence the $\mathrm{TiO}_{2}$ electron $-\mathrm{I}_{3}{ }^{-}$recombination reaction: (i) a steric blocking effect which reduces the concentration of $\mathrm{I}_{3}^{-}$at the interface of dye-covered $\mathrm{TiO}_{2}$ by physically blocking its approach; ${ }^{[6,32]}$ (ii) an increased $\mathrm{I}_{3}{ }^{-}$concentration at the $\mathrm{TiO}_{2}$ interface due to electrostatic forces, for example attraction of the negatively charged acceptor species in the presence of partial charges on the dye molecules; ${ }^{[6]}$ and (iii) an increased $\mathrm{I}_{3}{ }^{-}$concentration at the $\mathrm{TiO}_{2}$ interface due to dispersion forces, for example attraction of the acceptor species to the highly polarisable $\pi$-conjugated segments of dyes. ${ }^{[8]}$ In order to distinguish between these causes and to gain further insights into the origin of the longer electron lifetime observed for the dimer DSSCs, the composition of the redox electrolyte was varied. In addition to the measurements performed with the standard composition of Electrolyte Ia, DSSCs were also prepared using an electrolyte without $\mathrm{LiI}$ (0.7 M BMImI, 0.3 M tBP, $0.05 \mathrm{M} \mathrm{I}_{2}$ in acetonitrile, referred to as Electrolyte II) and without LiI and tBP (0.7 M DMPImI, $0.05 \mathrm{M} \mathrm{I}_{2}$ in acetonitrile, referred to as Electrolyte III). The $\mathrm{Li}^{+}$and tBP concentrations were varied since such species are known to have an influence on the charge recombination kinetics in DSSCs. ${ }^{[33-35]}$ Furthermore, lithium cation has also been reported to interact with dye molecules, ${ }^{[36]}$ and could therefore impact the recombination kinetics in the dimer DSSCs and monomer DSSCs differently. Photovoltaic performances for DSSCs containing each of these electrolytes are shown in Table 3. It should be noted that we have ascertained that varying the cation from BMImI to DMPImI makes very little difference to the photovoltaic performance (see Elecrtolytes $\mathbf{I a}$ and $\boldsymbol{I} \boldsymbol{b}$ in, Table 3), charge transport and recombination dynamics (data not shown). They can therefore be used interchangeably in Electrolytes II and III. 
Table 3. Photovoltaic performance parameters for DSSCs constructed from monoporphyrins P12 and P199 and dimer P10 with different electrolyte compositions.

\begin{tabular}{|c|c|c|c|c|c|c|}
\hline Dye & Electrolyte $^{[a-d]}$ & $\begin{array}{c}\text { Thickness }^{[\mathrm{e}]} \\
(\mu \mathrm{m})\end{array}$ & $\begin{array}{c}V_{o c} \\
(\mathrm{mV})\end{array}$ & $\begin{array}{c}J_{\mathrm{sc}} \\
\left.(\mathrm{mA} \mathrm{cm})^{-2}\right)\end{array}$ & FF & $\eta(\%)$ \\
\hline$P 10$ & Ia & 5.5 & 624 & 7.6 & 0.65 & 3.1 \\
\hline P199 & Ia & 5.4 & 585 & 6.6 & 0.67 & 2.6 \\
\hline$P 12$ & Ia & 5.2 & 575 & 6.0 & 0.65 & 2.3 \\
\hline $\begin{array}{l}P 10 \\
\text { (reduced dye } \\
\text { amount) }\end{array}$ & Ia & 5.4 & 536 & 1.5 & 0.66 & 0.54 \\
\hline $\begin{array}{l}P 199 \\
\text { (reduced dye } \\
\text { amount) }\end{array}$ & Ia & 5.2 & 456 & 0.84 & 0.59 & 0.23 \\
\hline$P 10$ & Ib & 5.3 & 624 & 6.8 & 0.64 & 2.7 \\
\hline P199 & $I b$ & 5.3 & 571 & 6.5 & 0.68 & 2.5 \\
\hline$P 12$ & $I b$ & 5.3 & 563 & 6.3 & 0.66 & 2.4 \\
\hline$P 10$ & II & 5.4 & 592 & 1.6 & 0.64 & 0.6 \\
\hline P199 & II & 5.2 & 553 & 1.6 & 0.65 & 0.58 \\
\hline P12 & II & 5.5 & 541 & 0.84 & 0.57 & 0.26 \\
\hline$P 10$ & III & 5.4 & 539 & 2.3 & 0.60 & 0.74 \\
\hline P199 & III & 5.2 & 522 & 2.2 & 0.62 & 0.69 \\
\hline$P 12$ & III & 5.2 & 473 & 1.4 & 0.56 & 0.36 \\
\hline \multicolumn{7}{|c|}{$\begin{array}{l}\text { [a] Electrolyte } \boldsymbol{I} \boldsymbol{a} \text { is } 0.1 \mathrm{M} \text { LiI, } 0.6 \mathrm{M} \text { DMPImI, } 0.5 \mathrm{M} \mathrm{tBP} \text { and } 0.05 \mathrm{M} \mathrm{I}_{2} \text { in acetonitrile. } \\
\text { [b] Electrolyte } \boldsymbol{I} \boldsymbol{b} \text { is } 0.1 \mathrm{M} \mathrm{LiI}, 0.6 \mathrm{M} \text { BMImI, } 0.5 \mathrm{M} \text { tBP and } 0.05 \mathrm{M} \mathrm{I}_{2} \text { in acetonitrile. } \\
\text { [c] Electrolyte } \boldsymbol{I I} \text { is } 0.7 \mathrm{M} \text { BMImI, } 0.5 \mathrm{M} \mathrm{tBP} \text { and } 0.05 \mathrm{M} \mathrm{I}_{2} \text { in acetonitrile. } \\
\text { [d] Electrolyte } \boldsymbol{I I I} \text { is } 0.7 \mathrm{M} \text { DMPImI, and } 0.05 \mathrm{M} \mathrm{I}_{2} \text { in acetonitrile. } \\
\text { [e] Cells were made without scattering layer and CDCA. }\end{array}$} \\
\hline
\end{tabular}

Figure 4 shows the electron lifetime for all dyes measured for DSSCs containing Electrolytes II and III.

For DSSCs with Electrolyte II, the trend in the electron lifetime appears to be the same as Electrolyte $\mathbf{I}$, with the dimer DSSCs exhibiting a longer lifetime than the monomer DSSCs. This result indicates that the $\mathrm{Li}^{+}$cation is not the origin of the difference between the dimer and monoporphyrin lifetimes. We note that the shorter lifetime values observed in Figure 4 (with Electrolyte II) compared to those in Figure 3 (with Electrolyte $\boldsymbol{I}$ ) are likely due to the higher $\mathrm{TiO}_{2}$ conduction band edge potential in the electrolyte without $\mathrm{Li}^{+}$as observed in previous studies, ${ }^{[37]}$ and determined in this study from the $V_{\text {oc }}$ Vs 
electron density plots at matched electron density (Figure 5). A higher conduction band potential provides a larger excess free energy driving force for the recombination between $\mathrm{TiO}_{2}$ electrons and the acceptor in the redox electrolyte, leading to increased recombination kinetics, and therefore a shorter electron lifetime. This negative conduction bands shift is also considered responsible for the significant reduction in the photocurrent observed from devices containing Electrolytes $\mathbf{I I}$ and $\mathbf{I I I}$ in comparison to those containing Electrolyte $\boldsymbol{I} \boldsymbol{b}$. The more negative conduction band reduces the overlap between the dye LUMO and the density of acceptor states in $\mathrm{TiO}_{2}$, resulting in a reduced photocurrent.

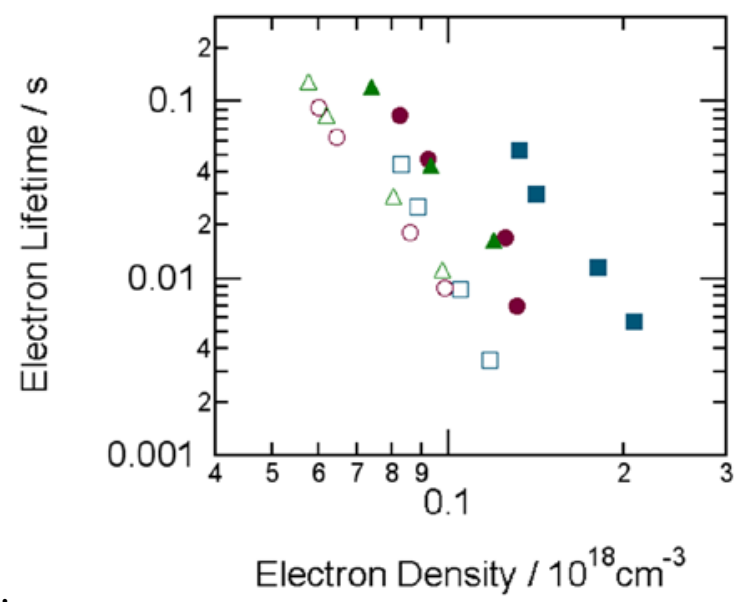

Figure 4. Electron lifetime vs electron density for DSSCs using P199 (circles), P12 (triangles) and P10 (squares) with Electrolyte II (closed) and Electrolyte III (open).

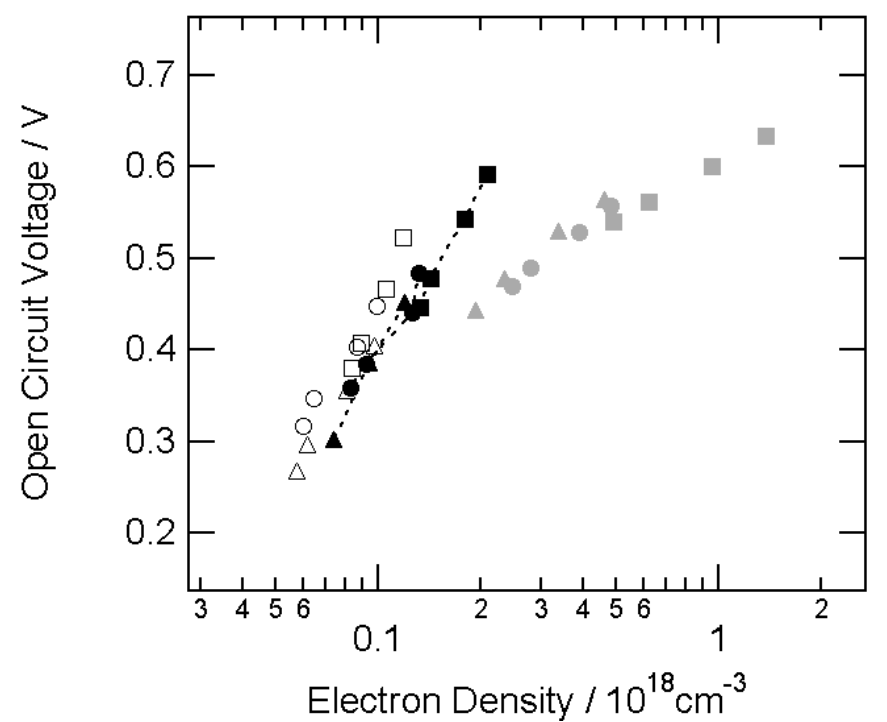

Figure 5. $V_{\text {oc }}$ Vs electron density for DSSCs using $\boldsymbol{P} 199$ (circles), $\boldsymbol{P} 12$ (triangles) and $\boldsymbol{P} 10$ (squares) and containing Electrolyte Ib (grey, closed) with Electrolyte II (black, closed) and Electrolyte III (open). 
Conversely for devices prepared without tBP using Electrolyte III, Figure 4 indicates that the lifetime of dimer DSSCs was comparable to that of the monomer DSSCs. Furthermore, a comparison between all dyes for devices containing Electrolytes II (with tBP) and III (no tBP) shows that the electron lifetime of all dyes is improved in the presence of tBP. This improvement is most pronounced for the dimer molecule, leading to its longer lifetime in comparison to the monomer DSSCs. This observation implies that the presence of tBP in the electrolyte affects the dimer and monomer differently. We note that tBP molecule has recently been reported to interact with dye molecules. ${ }^{\text {[38-39] }}$ One possible explanation for such an effect is an interaction of tBP molecules with the porphyrin dyes, creating a bulky dye structure. We have indeed observed a systematic red-shift in the absorption spectra of similar porphyrin dyes as the concentration of tBP is increased (data not shown), implying their interactions. If the tBP does indeed interact with the dye molecules for these sensitisers, then the bulky structure could then prevent the approach of $\mathrm{I}_{3}^{-}$acceptor species to the $\mathrm{TiO}_{2}$ surface. Since the dimer has multiple $\mathrm{Zn}$ atoms, this effect could be enhanced in comparison to the monoporphyrin dyes. Another effect could be that the coordination to the $\mathrm{Zn}$ atom would reduce the electrostatic force between the $\mathrm{Zn}$ cation and $\mathrm{I}_{3}{ }^{-}$.

To investigate whether the source of the dimer lifetime enhancement is a pure steric blocking affect (i), or whether partial charges (ii) or dispersion forces on the dye (iii) also influence the lifetime, measurements were performed at reduced dye loadings. A physical blocking effect is expected to be effective at high dye loadings and diminish largely at low dye surface coverage, whilst electrostatic or dispersive attraction forces decrease linearly with the amount of dyes. Therefore, at low dye surface coverages, parameters (ii) and (iii) are expected to be dominant in comparison to parameter (i). Accordingly, the concentration of monoporphyrin $\boldsymbol{P 1 9 9}$ and dimer $\boldsymbol{P 1 0}$ on the $\mathrm{TiO}_{2}$ surface was therefore reduced by approximately $95 \%$ (referred to as 'reduced' dye loading) of the dye coverage obtained under standard sensitisation conditions (referred to as ‘full' dye-loading). This was achieved by decreasing the dye bath concentration and shortening the dye uptake time from 2 hours to 30 minutes. When the dye loading of $\boldsymbol{P 1 0}$ and $\boldsymbol{P 1 9 9}$ was reduced, the electron lifetime became shorter for both dyes 
with respect to the 'full' coverage devices (Figure 3(b)). This result is attributed to a more sparsely covered surface with lower packing density, which allows the approach of the $\mathrm{I}_{3}{ }^{-}$to the $\mathrm{TiO}_{2}$ surface more readily. As seen for the 'full' dye coverage devices, there were no major differences between the $\boldsymbol{P 1 0}$ and $\boldsymbol{P 1 9 9}$ devices in the $D$ (Figure 3(c)) or the $\mathrm{TiO}_{2} E_{\mathrm{CB}}$ values (Figure 3(d)) at 'reduced' surface loadings. Furthermore, there was no longer a difference observed in the electron lifetimes between the dimer and monomer-sensitised devices at these 'reduced' dye loadings. This result supports that the longer electron lifetime observed for the $\boldsymbol{P 1 0}$ 'full' coverage devices is due to a steric blocking effect. The similar values of the lifetime at the reduced dye loading conditions suggests that both the dimer and monomer similarly attract acceptor species, implying no increase in dispersion force for the dimer. One concern raised by an anonymous reviewer is if a change in the orientation of the dyes affects the above considerations. At full dye loading conditions, based on the measured amount of adsorbed dyes, the dimers are expected to be nearly orthogonal to the $\mathrm{TiO}_{2}$ surface. ${ }^{[27]}$ If the orientation of dimers changed to parallel to the $\mathrm{TiO}_{2}$ surface at the reduced conditions, the concentration of porphyrin units near the surface would double, attracting more acceptor species and thus resulting in shorter electron lifetime in comparison to the case of the monomer under the same conditions and molar concentrations. Similarly, if the dimer exhibited larger attraction, e.g. dispersion, force and oriented more parallel to the $\mathrm{TiO}_{2}$ surface, more acceptors at the vicinity of the $\mathrm{TiO}_{2}$ surface would be expected. The similar observed lifetime values (and no increase in the attraction force) in Figure 4 imply that the dimer maintains its nearly orthogonal orientation even at reduced dye loading conditions.

\section{Implications to the strategy to improve the efficiency of dye-sensitized solar cells}

In order to retard charge recombination in DSSCs, the local concentration of $\mathrm{I}_{3}{ }^{-}$at the $\mathrm{TiO}_{2}$ surface should be minimized to reduce the probability of reverse charge transfer. This condition can be achieved by a careful consideration of the photosensitiser chemical structure. Dye molecules should ideally possess functional groups that enhance the blocking effect (i) and screen the electrostatic (ii) and dispersion forces (iii), since each of these conditions will reduce the amount of $\mathrm{I}_{3}{ }^{-}$attracted to the $\mathrm{TiO}_{2}$ 
surface. In addition, it is often desirable to enlarge the dye molecules in order to increase the absorption spectrum onset into the infrared spectral region. However, this strategy can be problematic for maintaining low recombination rates since it also increases the undesirable dispersion forces due to the higher polarizability of the larger dye molecules. To maximise the blocking effect and dye absorption spectrum whilst preventing an increase in the dispersive forces, attaching sterically encumbering groups, which do not exhibit $\pi$-conjugation to the core dye structure, has been shown to be an effective approach. ${ }^{[40]}$ We note that the dimer molecule studied here also conforms to this design strategy. The two porphyrin units do not maintain conjugation across both chromophores since they are oriented nearorthogonal to each other as we have previously shown using computational modelling. ${ }^{[9]}$ Thus, we have been able to introduce the blocking effect in dimer $\boldsymbol{P 1 0}$ without increasing the dispersion forces of the molecule which attract $\mathrm{I}_{3}{ }^{-}$to the $\mathrm{TiO}_{2}$ surface, leading to the observed increase in the electron lifetime of this dye. Coupled with improved light harvesting in the dimer-sensitised solar cells, these results indicate that the multichromophore approach without $\pi$ conjugation among each unit presents a pathway towards further efficiency improvements in dye sensitised solar cells, providing a new strategy to design sensitisers with enhanced absorption coefficients without facilitating charge recombination in DSSCs.

\section{CONCLUSIONS}

Increased electron lifetime by one order of magnitude at matched electron density has been reported for a porphyrin dimer-sensitised $\mathrm{TiO}_{2}$ solar cell in comparison to its monoporphyrin-sensitised analogue. This increase, which results in an improved open circuit voltage in operational devices, has been attributed to a steric blocking effect caused by the bulky dimer. This was evidenced by the decrease in the electron lifetime for the dimer at low dye surface concentrations. Furthermore, since the two porphyrin units are oriented orthogonal to each other, there is no overall increase in dispersion forces in the dimer which could counteract the steric blocking effect. The increased open circuit voltage is an additional benefit to the improved short circuit current produced by the enhanced light harvesting in the 
covalently linked porphyrin dimer, and suggests that the multichromophore dye approach without $\pi$ conjugation among each unit can be used to further increase device efficiency by allowing enhanced light absorption without facilitating additional charge recombination.

\section{ACKNOWLEDGEMENT}

Financial support of the Australian Research Council through Centre of Excellence, Discovery and LIEF grants is acknowledged. AJM is a recipient of an Australian Research Fellowship (DP110101369). Dr R. Katoh and Dr A. Furube are acknowledged for discussions.

\section{SUPPORTING INFORMATION AVAILABLE}

The change in $V_{o c}, J_{s c}$ and IPCE for monomer $(\boldsymbol{P} 199)$ and dimer $(\boldsymbol{P} 10)$ DSSCs sensitised using various dye bath concentrations and dye uptake times (Figures S1 and S2). The effect of chenodeoxycholic acid (CDCA) co-adsorber and a $\mathrm{TiO}_{2}$ scattering layer on the electron diffusion coefficients, lifetime and the $V_{\text {oc }}$ vs electron density plots for DSSCs sensitised with monomer $\boldsymbol{P} 12$ and dimer $\boldsymbol{P} 10$ (Figure S3). The effect of dye immersion time between 90 and 360 minutes on the electron diffusion coefficients, lifetime and the $V_{\text {ос }}$ vs electron density plots for DSSCs sensitised with dimer P10 (Figure S4). Current density voltage curves measured under AM 1.5 illumination and in the dark for DSSCs constructed without CDCA coadsorber and $\mathrm{TiO}_{2}$ scattering layers using monomers $\boldsymbol{P 1 9 9}$ and $\boldsymbol{P} 12$, and dimer $\boldsymbol{P} 10$. This information is available free of charge via the Internet at http://pubs.acs.org 


\section{REFERENCES}

[1] O'Regan, B.; Grätzel, M., A Low-Cost, High-Efficiency Solar Cell Based on Dye-Sensitised Colloidal $\mathrm{TiO}_{2}$ Films, Nature, 1991, 353, 737-740.

[2] Gregg, B. A.; Pichot, F.; Ferrere, S.; Fields, C. L., Interfacial Recombination Processes in DyeSensitised Solar Cells and Methods To Passivate the Interfaces, J. Phys. Chem. B, 2001, 105, 1422-1429.

[3] Jennings, J. R.; Liu, Y.; Wang, Q.; Zakeeruddin, S. M.; Grätzel, M., The Influence of Dye Structure on Charge Recombination in Dye-Sensitised Solar Cells , Phys. Chem. Chem. Phys., 2011, 13, 6637-6648.

[4] Wiberg, J.; Marinado, T.; Hagberg, D. P.; Sun, L.; Hagfeldt, A.; Albinsson, B., Effect of Anchoring Group on Electron Injection and Recombination Dynamics in Organic DyeSensitised Solar Cells, J. Phys. Chem. C, 2009, 113, 3881-3886.

[5] Mozer, A. J.; Wagner, P.; Officer, D. L.; Wallace, G. G.; Campbell, W. M.; Miyashita, M.; Sunahara, K.; Mori, S, The Origin of Open Circuit Voltage of Porphyrin-Sensitised TiO2 Solar Cells, Chem. Commun., 2008, 4741-4753.

[6] Miyashita, M.; Sunahara, K.; Nishikawa, T.; Uemura, Y.; Koumura, N.; Hara, K.; Mori, A.; Abe, T.; Suzuki, E.; Mori, S., Interfacial Electron-Transfer Kinetics in Metal-Free Organic DyeSensitised Solar Cells: Combined Effects of Molecular Structure of Dyes and Electrolytes, J. Am. Chem. Soc., 2008, 130, 17874-17881.

[7] O'Regan, B. C.; López-Duarte, I.; Martínez-Díaz, M. V. ; Forneli, A. ; Albero, J.; Morandeira, A.; Palomares, E.; Torres, T. ; Durrant, J. R., Catalysis of Recombination and Its Limitation on Open Circuit Voltage for Dye Sensitised Photovoltaic Cells Using Phthalocyanine Dyes, J. Am. Chem. Soc., 2008, 130, 2906-2907. 
[8] Marinado, T.; Nonomura, K.; Nissfolk, J.; Karlsson, M. K.; Hagberg, D. P.; Sun, L.; Mori, S.; Hagfeldt, A., How the Nature of Triphenylamine-Polyene Dyes in Dye-Sensitised Solar Cells Affects the Open-Circuit Voltage and Electron Lifetimes, Langmuir, 2010, 24, 2592-2598.

[9] London, F., The General Theory of Molecular Forces, Trans. Faraday Soc., 1937, 33, 8b-26.

[10] Cameron, P. J.; Peter, L. M., Characterization of Titanium Dioxide Blocking Layers in DyeSensitised Nanocrystalline Solar Cells, J. Phys. Chem. B, 2003, 107, 14394-14400.

[11] Allegrucci, A.; Lewcenko, N. A.; Mozer, A. J.; Dennany, L.; Wagner, P.; Officer, D. L.; Sunahara, K.; Mori, S.; Spiccia, L., Improved Performance of Porphyrin-Based Dye Sensitised Solar Cells by Phosphinic Acid Surface Treatment, Ener. Environ. Sci., 2009, 2, 1069-1073.

[12] Feldt, S. M.; Cappel, U. B.; Johansson, E. M. J.; Boschloo, G.; Hagfeldt, A., Characterization of Surface Passivation by Poly(methylsiloxane) for Dye-Sensitised Solar Cells Employing the Ferrocene Redox Couple, J. Phys. Chem. C, 2010, 114, 10551-10558.

[13] Neale, N. R.; Kopidakis, N.; van de Lagemaat, J.; Grätzel, M.; Frank, A. J., Effect of a Coadsorbent on the Performance of Dye-Sensitised TiO2 Solar Cells: Shielding versus Band-Edge Movement, J. Phys. Chem. B, 2005, 109, 23183-23189.

[14] Lee, K.-M.; Suryanarayanan, V.; Ho, K.-C.; Thomas, K. R. J.; Lin, J. T., Effects of Co-adsorbate and Additive on the Performance of Dye-Sensitised Solar Cells: A Photophysical Study, Sol. Ener. Mater. Sol. Cells, 2007, 91, 1426-1431.

[15] Wang, M.; Grätzel, C.; Moon, S.-J.; Humphry-Baker, R.; Rossier-Iten, N.; Zakeeruddin, S. M.; Grätzel, M, Surface Design in Solid-State Dye Sensitised Solar Cells: Effects of Zwitterionic Co-adsorbents on Photovoltaic Performance, Adv. Funct. Mater., 2009, 19, 2163-2172.

[16] Zhang, Z.; Zakeeruddin, S. M.; O’Regan, B. C.; Humphry-Baker, R.; Grätzel, M., Influence of 4-Guanidinobutyric Acid as Coadsorbent in Reducing Recombination in Dye-Sensitised Solar Cells, J. Phys. Chem. B, 2005, 109, 21818-21824.

[17] Koumura, N. Wang, Z.-S., Mori, S.; Miyashita, M.; Suzuki, E.; Hara, K.; Alkyl-Functionalized Organic Dyes for Efficient Molecular Photovoltaics, J. Am. Chem. Soc., 2006, 128, 14256-14257. 
[18] Eu, S.; Katoh, T.; Umeyama, T.; Matano, Y.; Imahori, H., Synthesis of Sterically Hindered Phthalocyanines and Their Applications to Dye-Sensitised Solar Cells., Dalt. Trans., 2008, 40, 5476-5483.

[19] Clifford, J. N.; Yahioglu, G.; Milgrom, L. R.; Durrant, J. R., Molecular Control of Recombination Dynamics in Dye Sensitised Nanocrystalline $\mathrm{TiO}_{2}$ Films, Chem. Commun., 2002, $1260-1261$.

[20] Mori, S.; Nagata, M.; Nakahata, Y.; Yasuta, K.; Goto, R.; Kimura, M.; Taya, M., Enhancement of Incident Photon-to-Current Conversion Efficiency for Phthalocyanine-Sensitised Solar Cells by 3D Molecular Structuralization, J. Am. Chem. Soc., 2010, 132, 4054-4055.

[21] Yella, A.; Lee, H.-W.; Tsao, H. N.; Yi, C.; Chandiran, A. K.; Nazeeruddin, M. K.; Diau, E. W.G.; Yeh, C.-Y.; Zakeeruddin, S. M.; Grätzel, M., Porphyrin-Sensitised Solar Cells with Cobalt (II/III)-Based Redox Electrolyte Exceed 12 Percent Efficiency, Science, 2011, 334, 629-634.

[22] Warnan, J.; Pellegrin, Y.; Blarta, E.; Odobel, F., Supramolecular light harvesting antennas to enhance absorption cross-section in dye-sensitised solar cells, Chem. Commun., 2012, 48, 675677.

[23] Park, J. K.; Chen, J.; Lee, H. R.; Park, S. W.; Shinokubo, H.; Osuka, A.; Kim D., Doubly $\beta$ Functionalized Meso-Meso Directly Linked Porphyrin Dimer Sensitisers for Photovoltaics, J. Phys. Chem. C, 2009, 113, 21956-21963.

[24] Wu, H.-P.; Ou, Z.-W.; Pan, T.-Y. ; Lan, C.-M.; Huang, W.-K. ; Lee, H.-W. ; Reddy, N. M. ; Chen, C.-T.; Chao, W.-S.; Yeh, C.-Y.; Diau, E. W.-G., Molecular engineering of cocktail cosensitization for efficient panchromatic porphyrin-sensitised solar cells, Energy Environ. Sci., 2012, 5, 9843-9848.

[25] Mai, C.-L.; Huang, W.-K.; Lu, H.-P.; Lee, C.-W.; Chiu, C.-L.; Liang, Y.-R.; Diau, E. W.-G.; Yeh, C.-Y., Synthesis and Characterization of Diporphyrin Sensitisers for Dye-Sensitised Solar Cells, Chem. Commun., 2010, 46, 809-811. 
[26] Liu, Y.; Lin, H.; Dy, J. T.; Tamaki, K.; Nakazaki, J.; Nakayama, D.; Uchida, S.; Kubo, T.;

Segawa, H., $N$-fused Carbazole-Zinc Porphyrin-Free-Base Porphyrin Triad for Efficient NearIR dye-Sensitised Solar Cells, Chem. Commun., 2011, 47, 4010-4012.

[27] Mozer, A. J.; Griffith, M. J.; Tsekouras, G.; Wagner, P.; Wallace, G. G.; Mori, S.; Sunahara, K.;

Miyashita, M.; Earles, J. C.; Gordon, K. C.; Du, L.; Katoh, R.; Furube, A.; Officer, D. L., Zn-Zn Porphyrin Dimer-Sensitised Solar Cells: Towards 3-D Light Harvesting, J. Am. Chem. Soc., 2009, 131, 15621-15623.

[28] Nakade, S.; Kanzaki, T.; Wada, Y.; Yanagida, S., Stepped Light-Induced Transient Measurements of Photocurrent and Voltage in Dye-Sensitised Solar Cells: Application for Highly Viscous Electrolyte Systems, Langmuir, 2005, 21, 10803-10807.

[29] Duffy, N. W.; Peter, L. M.; Rajapakse, R. M. G.; Wijayantha, K. G. U., A Novel Charge Extraction Method for the Study of Electron Transport and Interfacial Transfer in Dye Sensitised Nanocrystalline Solar Cells, Electrochem. Commun., 2000, 2, 658-662.

[30] Peter, L. M.; Duffy, N. W.; Wang, R. L.; Wijayantha, K. G. U., Transport and Interfacial Transfer of Electrons in Dye-Sensitised Nanocrystalline Solar Cells, J. Electroanal. Chem., 2002, 524-525, 127-136.

[31] Peter, L., “Sticky Electrons”: Transport and Interfacial Transfer of Electrons in the DyeSensitised Solar Cell, Acc. Chem. Res., 2009, 42, 1839-1847.

[32] Nakade, S.; Kanzaki, T.; Kubo, W.; Kitamura, T.; Wada, Y.; Yanagida, S., Role of Electrolytes on Charge Recombination in Dye-Sensitised TiO2 Solar Cell (1): The Case of Solar Cells Using the I-/I3- Redox Couple, J. Phys. Chem. B, 2005, 109, 3480-3487.

[33] Kopidakis, N.; Benkstein, K. D.; van de Lagemaat, J.; Frank, A. J., Transport-Limited Recombination of Photocarriers in Dye-Sensitised Nanocrystalline TiO2 Solar Cells, J. Phys. Chem. B, 2003, 107, 11307-11315. 
[34] Yu, Q.; Wang, Y.; Yi, Z.; Zu, N.; Zhang, J.; Zhang, M.; Wang, P., High-Efficiency DyeSensitised Solar Cells: The Influence of Lithium Ions on Exciton Dissociation, Charge Recombination, and Surface States, ACS Nano, 2010, 4, 6032-6038.

[35] Boschloo, G.l Häggman, L.; Hagfeldt, A., Quantification of the Effect of 4-tert-Butylpyridine Addition to I-/I3- Redox Electrolytes in Dye-Sensitised Nanostructured TiO2 Solar Cells, J. Phys. Chem. B, 2006, 110, 13144-13150.

[36] Kuang, D.; Klein, C.; Snaith, H. J.; Moser, J.-E.; Humphry-Baker, R.; Comte, P.; Zakeeruddin, S. M.; Grätzel, M., Ion Coordinating Sensitiser for High Efficiency Mesoscopic Dye-Sensitised Solar Cells: Influence of Lithium Ions on the Photovoltaic Performance of Liquid and SolidState Cells, Nano Lett., 2006, 6, 769-773.

[37] Liu, Y.; Hagfeldt, A.; Xiao, X.-R.; Lindquist, S.-E., Investigation of Influence of Redox Species on the Interfacial Energetics of a Dye-Sensitised Nanoporous $\mathrm{TiO}_{2}$ Solar Cell, Sol. Ener. Mater. Sol. Cells, 1998, 55, 267-281.

[38] Gao, R.; Wang, L.; Geng, Y.; Ma, B.; Zhu, Y.; Dong, H.; Qiu, Y., Interface Modification Effects of 4-tertbutylpyridine Interacting with N3 Molecules in Quasi-Solid Dye-Sensitised Solar Cells, Phys. Chem. Chem. Phys., 2011, 13, 10635-10640.

[39] Zhang, K.; Zhang, S.; Sodeyama, K.; Yang, X.; Chen, H.; M.; Yanagida, Tateyama, Y.; Han, L., A New Factor Affecting the Performance of Dye-Sensitised Solar Cells in the Presence of 4-tertButylpyridine, Appl. Phys. Expr. 2012, 5, 042303-042305.

[40] Nishida, J.; Masuko, T.; Cui, Y.; Hara, K.; Shibuya, H.; Ihara, M.; Hosoyama, Y.; Goto, R.; Mori, S.; Yamashita, Y., Molecular Design of Organic Dye toward Retardation of Charge Recombination at Semiconductor/Dye/Electrolyte Interface: Introduction of Twisted $\pi$-Linker, $J$. Phys. Chem. C, 2010, 114, 17920-17925. 